\title{
Global Lung Initiative spirometry references in healthy 3-15-year-old French children
}

The Global Lung Initiative (GLI) Task Force published references for spirometry derived from data collated from a large population of healthy individuals aged 3-95 years, from 26 countries [1]. However data from French children were not included in these equations and external validation of the references is recommended [2]. Our study's aim was to compare z-score values and distributions obtained using the references of ZAPLETAL et al. [3,4] (Zap-Ref) for preschool [3] and school children [4] currently used in France with those obtained using the GLI's references (GLI-Ref) as applied to data from 3-15 year-old healthy French children from northern France.

The study received approval from the institutional ethics committee (reference 98/23) and, from September 2006 to November 2007, was explained to the children from four schools in the Nord-Pas de Calais region of northern France and their parents to obtain their written informed consent. The presence of underlying respiratory disease was assessed with a questionnaire completed by a parent of each child: 500 children without parent-reported respiratory disease or chronic disease affecting lung function (all Caucasian) were recruited. 58 children were excluded: active smoking: $n=2$; respiratory infection in the month preceding the spirometry: $n=51$; pre-schoolers unable to perform at least two acceptable maximal expiratory flow-volume curves: $\mathrm{n}=5$. Excluded children were older $(9.91 \pm 3.30$ years versus $8.32 \pm 3.24$ years, $\mathrm{p}<0.001)$ and taller $(138.4 \pm 20.61 \mathrm{~cm}$ versus $130.3 \pm 19.73 \mathrm{~cm}, \mathrm{p}=0.004)$, but their body mass index $\mathrm{z}$-scores $(0.32 \pm 1.37$ versus $0.39 \pm 1.29, \mathrm{p}=0.70)$ and the percentage of boys $(39.7 \%$ versus $48.6 \%, \mathrm{p}=0.20)$ were comparable to those of the 442 asymptomatic included children (3.0-14.8 years of age).

Spirometry was performed, at school, by skilled paediatric pulmonary nurses using Masterscreen Pneumo (Erich Jaeger, Wurzburg, Germany). Acceptability and repeatability criteria were applied following international recommendations for children aged $<6$ years [5] and children aged $\geqslant 6$ years [6]. Forced vital capacity (FVC), forced expiratory volume in $1 \mathrm{~s}\left(\mathrm{FEV}_{1}\right)$ and the $\mathrm{FEV}_{1} / \mathrm{FVC}$ ratio were obtained in $96.6 \%$, $98.0 \%$ and $95.5 \%$ of the subjects $(<5 \%$ of missing data), respectively. Results were expressed as $\mathrm{z}$-scores derived from both Zap-Ref and the GLI-Ref [1, 3, 4]. The lower limit of normal (LLN) was defined as $-1.645 \mathrm{z}$-score value $[1,7,8]$ and the upper limit of normal (ULN) as $+1.645 \mathrm{z}$-score value. Proportions of children with index values $<$ LLN or $>$ ULN were calculated for both the Zap-Ref and GLI-Ref.

Quantitative variables were expressed as the mean and standard deviation (SD) in cases of Gaussian distribution. Normality of distributions was checked graphically and using the Shapiro-Wilk test. Categorical variables were expressed as frequencies and percentages. Data were analysed using SAS software version 9.4 (SAS Institute Inc., Cary, NC, USA) and all statistical tests were performed with a two-tailed alpha risk of 0.05 .

The characteristics of the children are presented in table $1.32 \%$ of children were less than 6 years of age (pre-schoolers). Girls had a larger $\mathrm{FEV}_{1} / \mathrm{FVC}$ ratio than boys when using Zap-Ref but this difference was not observed when using the GLI-Ref.

When using Zap-Ref, whatever the sex, all mean calculated values were significantly different from zero, ranging from -0.35 to +0.67 , and all sDs were $>1$, ranging from 1.32 to 1.75 (table 1 ). In both groups,

@ERSpublications

Global Lung Initiative spirometry references satisfactorily fit data of healthy 3 - to 15 -year-old French children http://bit.ly/2Z2922R

Cite this article as: Nève V, Machuron F, Behal H, et al. Global Lung Initiative spirometry references in healthy 3-15-year-old French children. ERJ Open Res 2019; 5: 00023-2019 [https:// doi.org/10.1183/23120541.00023-2019].

Copyright $\odot$ ERS 2019. This article is open access and distributed under the terms of the Creative Commons Attribution NonCommercial Licence 4.0. 
TABLE 1 Spirometry results and proportion of children with spirometry data below the lower limit of normal (LLN) or above the upper limit of normal (ULN)

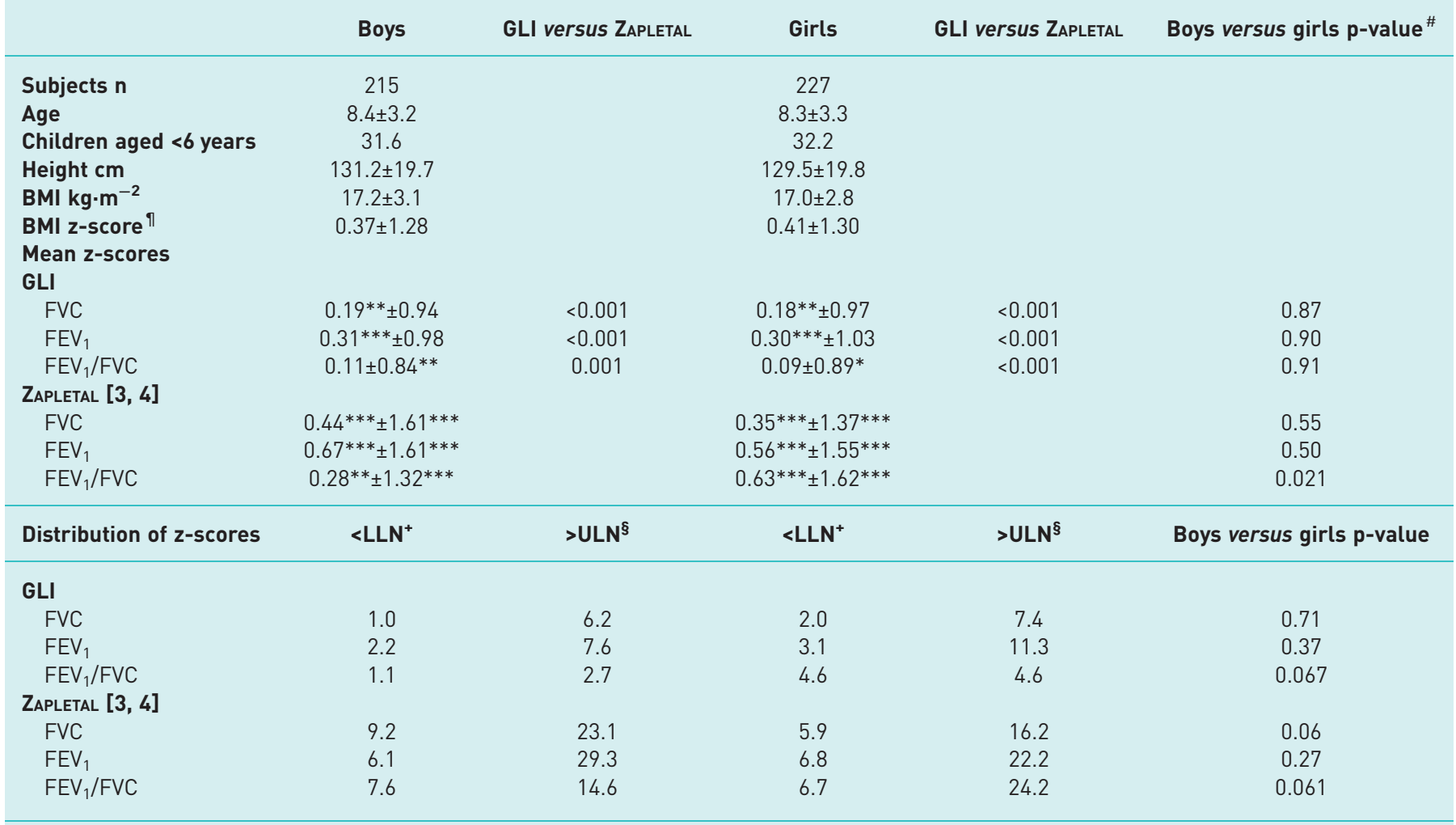

Data are presented as mean z-scores \pm SD or \%, unless otherwise stated. BMI: body mass index; FVC: forced vital capacity, FEV ${ }_{1}$ : forced expiratory volume in $1 \mathrm{~s} .{ }^{\#}$ : comparisons of z-score difference performed by Student's t-test. Comparison of proportions of subjects relative to the LLN and ULN were performed by Chi-squared test or Fisher's exact test except when observed frequencies were <5. Means were compared to 0 using paired Student's t-tests and sDS were compared to 1 using Chi-squared tests for variance; " : RoLLAND-CACHERA et al. [9]; ${ }^{+}:<-1.645 z$-score value ; ${ }^{\S}$ : $>1.645 z$-score value. ${ }^{*}: p<0.05 ;{ }^{* *}: p<0.01 ;{ }^{* * *}: p<0.001$.

proportions of children outside the limits of normality far exceeded 5\% (5.9-29.3\%) for each of the respiratory indices (table 1). No significant difference between boys and girls was observed. Considering the age classes, a larger proportion of pre-schoolers had a $\mathrm{FEV}_{1}<\mathrm{LLN}$ (15.9\% versus $2.7 \%$ of school-age children, $\mathrm{p}<0.001)$ and a larger proportion of pre-schoolers had $\mathrm{FEV}_{1} / \mathrm{FVC}$ ratios $<\mathrm{LLN}(23.5 \%$ versus $1.4 \%$ of school-age children, $\mathrm{p}<0.001)$, while no difference was observed for FVC $(9.7 \%$ of pre-schoolers had a FVC $<$ LLN versus $6.3 \%$ of school-age children, $\mathrm{p}=0.52$ ).

Using the GLI-Ref, $\mathrm{z}$-scores for all indices were significantly different from $\mathrm{z}$-scores obtained using Zap-Ref, whatever the sex (table 1) with $\mathrm{FEV}_{1}, \mathrm{FVC}$ and $\mathrm{FEV}_{1} / \mathrm{FVC}$ ratio absolute $\mathrm{z}$-score values that were closer to zero (corresponding to a perfect fit of the reference to our sample). A lower proportion of subjects in each group fell outside the limit of normality $(<\mathrm{LLN}$ or $>\mathrm{ULN})$. Comparing the age-classes, though a larger proportion of pre-schoolers had indices <LLN compared with school-age children (FVC: $4.4 \%$ versus $0.3 \%, \mathrm{p}=0.002 ; \mathrm{FEV}_{1}: 7.1 \%$ versus $1.1 \%, \mathrm{p}=0.003 ; \mathrm{FEV}_{1} / \mathrm{FVC}$ ratios: $6.1 \%$ versus $1.8 \%$, $\mathrm{p}=0.004$ ), the proportions outside the limits of normality were nonetheless smaller using the GLI-Ref than with Zap-Ref.

The GLI-Ref values for spirometry better fit a contemporary sample of healthy children from northern France than the Zap-Ref values; however, the fit of the prediction depended upon the spirometric index evaluated: GLI-Ref produced $\mathrm{FEV}_{1}, \mathrm{FVC}$ and $\mathrm{FEV}_{1} / \mathrm{FVC}$ ratio mean $\mathrm{z}$-score values that were closer to zero than those obtained using Zap-Ref, and SD values were approximately 1 in all groups, except for $\mathrm{FEV}_{1} /$ FVC ratio in boys. In addition, a proportion closer to $5 \%$ in each group fell outside the limit of normality and, finally, the sex difference observed with Zap-Ref disappeared when using the GLI-Ref. Similar results were obtained in healthy adults and when comparing the European Community for Steel and Coal values and GLI-Ref $[10,11]$. GLI-Ref values were also found to be applicable to healthy populations that included children, namely Australian subjects aged 4-80 years [12], multi-ethnic English children [13], sub-Saharan 
African children [14] and Norwegian adolescents [15]. The fitting improvement observed with the GLI-Ref was particularly marked in our pre-schoolers with fewer pre-schoolers having an $\mathrm{FEV}_{1}$ or an $\mathrm{FEV}_{1} / \mathrm{FVC}$ ratio below the LLN (7.1\% and $6.1 \%$, respectively, versus $15.9 \%$ and $23.5 \%$, respectively, compared with Zap-Ref) and these proportions were closer to 5\% (5\% of observations below the fifth percentile defined by a $\mathrm{z}$-score of -1.645 corresponding to a perfect fit of the reference to our sample). However, in our healthy population, a FVC <LLN was observed in fewer healthy boys and girls $(1.0 \%$ and $2.0 \%$, respectively) while the proportion with an $\mathrm{FEV}_{1} / \mathrm{FVC}$ ratio $<\mathrm{LLN}$ was observed in $1.1 \%$ of healthy boys. The SDs of $\mathrm{z}$-scores were 0.84 in boys and 0.89 in girls for $\mathrm{FEV}_{1} / \mathrm{FVC}$ ratios indicating a greater homogeneity of these parameters in our population. Accordingly, the LLN for these indices in our population may need adjustment to a slightly higher level (for $\mathrm{FEV}_{1} / \mathrm{FVC}$ in boys to $-1.233 \mathrm{z}$-score and in girls to $-1.400 \mathrm{z}$-score). Though the GLI-Ref provided a good fit on data from sub-Saharan African children [14], the authors also observed that, owing to a relatively low scatter, the 5th percentile corresponded to $-1.3 \mathrm{z}$-score in boys and $-1.5 \mathrm{z}$-score in girls; cut-offs that are similar to those calculated in our population.

The strength of our study is that this assessment of the GLI-Ref on a contemporary sample of the population of northern France was performed on a sample of sufficient size ( $>150$ subjects of each sex) to make a reliable evaluation of the applicability of reference values for spirometry [16]. Our study also included pre-schoolers, hitherto obtained by only one previous study [12].

In conclusion, our study shows that the GLI-Ref for spirometry better fit a contemporary sample of the healthy French population of Northern France than Zap-Ref, with fitting improvement being particularly prominent in pre-schoolers. However, for some indices, the LLN in our population may need adjustment to a slightly higher level.

Véronique Nève $^{1,2}$, François Machuron ${ }^{2,3}$, Hélène Behal ${ }^{2,3}$, Michael Howsam $^{2,4}$, Catherine-Marie Methlin ${ }^{1}$, Christelle Delille ${ }^{1}$, Georges Baquet ${ }^{5}$ and Régis Matran ${ }^{1,2}$

${ }^{1} \mathrm{CHU}$ de Lille, EA 4483, Explorations Fonctionnelles Respiratoires, Lille, France. ${ }^{2}$ Univ Lille, Lille, France. ${ }^{3} \mathrm{CHU}$ Lille, EA 2694 - Santé Publique: Épidémiologie et Qualité des Soins, Unité de Biostatistiques, Lille, France. ${ }^{4}$ Lille Inflammation Research International Centre (LIRIC) - UMR 995, Lille, France. ${ }^{5}$ Univ. Lille, Univ. Artois, Univ. Littoral Côte d'Opale, EA 7369 - URePSSS - Unité de Recherche Pluridisciplinaire Sport Santé Société, Lille, France.

Correspondence: Véronique Nève, Service d'Explorations Fonctionnelles Respiratoires, Hôpital Calmette, CHU de Lille, 2, Avenue Oscar Lambret, 59000 Lille, France. E-mail: veronique.neve@chru-lille.fr

Received: 08 March 2018 | Accepted after revision: 10 June 2019

Acknowledgements: The authors are grateful to the children from the schools of Illies, Herlies and La Bassée (all France) who enthusiastically participated in this study and to the Inspection d'Académie of Lille (France).

Conflict of interest: None declared.

\section{References}

1 Quanjer PH, Stanojevic S, Cole TJ, et al. Multi-ethnic reference values for spirometry for the 3-95-yr age range: the global lung function 2012 equations. Eur Respir J 2012; 40: 1324-1343.

2 Quanjer PH, Stanojevic S. Do the Global Lung Function Initiative 2012 equations fit my population? Eur Respir J 2016; 48: 1782-1785.

3 Zapletal A, Chalupova J. Forced expiratory parameters in healthy preschool children (3-6 years of age). Pediatr Pulmonol 2003; 35: 200-207.

4 Zapletal A, Paul T, Samanek N. Die Bedeutung heutiger Methoden der Lungen-funktionsdiagnostik zur Feststellung einer Obstruktion der Atemwege bei Kindern und Jugendlichen [Significance of contemporary methods of lung function testing for the detection of airway obstruction in children and adolescents]. $Z$ Erkr Atm-Org 1977; 149: 343-371.

5 Beydon N, Davis SD, Lombardi E, et al. An official American Thoracic Society/European Respiratory Society statement: pulmonary function testing in preschool children. Am J Respir Crit Care Med 2007; 175: 1304-1345.

6 Miller MR, Hankinson J, Brusasco V, et al. Standardisation of spirometry. Eur Respir J 2005; 26: 319-338.

7 Pellegrino R, Viegi G, Brusasco V, et al. Interpretative strategies for lung function tests. Eur Respir J 2005; 26: 948-968.

8 Quanjer PH, Tammeling GJ, Cotes JE, et al. Lung volumes and forced ventilatory flows. Report Working Party Standardization of Lung Function Tests, European Community for Steel and Coal. Official Statement of the European Respiratory Society. Eur Respir J Suppl 1993; 16: 5-40.

9 Rolland-Cachera MF, Cole TJ, Sempé M, et al. Body mass index variations: centiles from birth to 87 years. Eur J Clin Nutr 1991; 45: 13-21.

10 Backman H, Lindberg A, Sovijarvi A, et al. Evaluation of the global lung function initiative 2012 reference values for spirometry in a Swedish population sample. BMC Pulm Med 2015; 25: 26. 
11 Hulo S, de Broucker V, Giovannelli J, et al. Global Lung Function Initiative reference equations better describe a middle-aged, healthy French population than the European Community for Steel and Coal values. Eur Respir J 2016; 48: 1779-1781.

12 Hall GL, Thompson BR, Stanojevic S, et al. The Global Lung Initiative 2012 reference values reflect contemporary Australasian spirometry. Respirology 2012; 17: 1150-1151.

13 Bonner R, Lum S, Stocks J, et al. Applicability of the global lung function spirometry equations in contemporary multiethnic children. Am J Respir Crit Care Med 2013; 188: 515-516.

14 Arigliani M, Canciani MC, Mottini G, et al. Evaluation of the Global Lung Initiative 2012 reference values for spirometry in African children. Am J Respir Crit Care Med 2017; 195: 229-236.

15 Langhammer A, Johannessen A, Holmen TL, et al. Global Lung Function Initiative 2012 reference equations for spirometry in the Norwegian population. Eur Respir J 2016; 48: 1602-1611.

16 Quanjer PH, Stocks J, Cole TJ, et al. Influence of secular trends and sample size on reference equations for lung function tests. Eur Respir J 2011; 37: 658-664. 